\title{
El huerto de Melibea: Parodia y subversión de un topos medieval
}

\author{
Alfredo J. Sosa-Velasco \\ University of Florida
}

\begin{abstract}
Melibea. Canta más, por mi vida, Lucrecia, que me huelgo en oyrte, mientra viene aquel señor, y muy passo entre estas verduricas, que no nos oyrán los que passaren (320).
\end{abstract}

\section{Introducción}

CuANDo el estudio de la (re)presentación del huerto de Melibea, ${ }^{1}$ como uno de los componentes espaciales que integran la trama de La Celestina (LC), ${ }^{2}$ ha sido abordado por la crítica literaria se ha hecho obviamente

1. A lo largo de este trabajo se emplean los términos «huerto» $y$ «jardín» como sinónimos del tradicional hortus clausus. A través de la bibliografía disponible sobre el tema en lengua española se ha comprobado que el término de preferencia utilizado por los estudiosos es el de "huerto", haciéndose alusión a los tipos de jardín (vegetal o frutal) más que al simple "jardín» al que la bibliografía en inglés ("garden») se refiere. Así que debido a la amplitud de las fuentes secundarias usadas para este trabajo se ha preferido intercambiar dichos términos sin que por ello se haga diferencia entre las posibles connotaciones que cada uno de ellos tiene en el idioma español.

2. En este trabajo se ha elegido como texto literario de La Celestina el editado por Dorothy S. Severin (1997), correspondiente a la primera versión conocida de la Tragicomedia de Calisto y Melibea publicada en Zaragoza en 1507. Si esta edición es empleada como texto base, la estudiosa ha suplido ciertas "corrupciones textuales» de ésta con las ediciones de la Comedia publicada en Toledo en 1500 y de la Tragicomedia publicada en Valencia en 1514. Como bien señala Severin acerca de la edición de 1507, si «no es muy buena ni muy completa, puesto que fue impresa en un año de peste —así lo indica Keith Whinnom [1966]» (45), al menos «resulta tener muchas menos corrupciones textuales que las impresiones posteriores, cosa que se ha encargado de demostrar Erna Berndt Kelly» (45).

En cuanto a los problemas relacionados con la autoría de la obra que tanto la crítica literaria de La Celestina ha señalado, en este trabajo se ha optado por aceptar lo que muchos de los especialistas hoy en día parecen dar por hecho: la afirmación de que el primer acto es obra de un autor desconocido al cual Fernando de Rojas añadió los capítulos restantes. Para ello, sólo es necesario cotejar la carta «El autor a un amigo» que aparece en los textos de la Comedia 
desde muy diferentes ángulos. Entre los diversos trabajos que han salido a la luz, cabe destacar los estudios propuestos por Orozco Díaz (1968), Weinberg (1971), Truesdell (1973), Shipley (1974), Stamm (1977) y Lecertua (1978). Si bien todos ellos se aproximan al estudio del huerto de Melibea con distintos propósitos, que abarcan desde la función, representación y significación hasta el uso del jardín como componente espacial fundamental de la obra, al final el producto último de algunos de estos análisis es el mismo: no llegan a ser lo suficientemente completos o esclarecedores como para entender la importancia o significación que el huerto de Melibea tiene dentro de LC.

Lo que propone el presente análisis es un replanteamiento de los estudios realizados hasta ahora con el fin de elaborar una visión de conjunto que permita explorar los posibles significados y funciones (así como connotaciones) que el huerto de Melibea tiene dentro del texto de LC. ${ }^{3}$ Se entiende así el cronotopo como unidad de espacio y tiempo en la que la representación del huerto es una variación del locus amoenus tradicional, que se vincula con el contexto histórico social en el que vive el autor y con la situación de los conversos y marginados de entonces.

El objetivo de este trabajo es pues el estudio de las diferentes relaciones entre los múltiples significados y las distintas funciones que se superponen en LC como productos de la representación que del huerto de Melibea se realizan. Comprender la fluidez de las relaciones entre representación, por un lado, y significación misma del huerto, por otro, es la meta de este análisis. ${ }^{4}$ Se toma en consideración al «huerto de Melibea» (hortus clausus) como una reformulación del cronotopo tradicional espacial cerrado del

(Toledo, 1500) y de la Tragicomedia (Valencia, 1514) y que falta asimismo en la edición de la Comedia de Burgos de 1499. En dicha carta, Fernando de Rojas señala que él encontró el manuscrito del primer acto que no tenía firma de su autor, «el qual, según algunos dizen, fue Juan de Mena, e según otros, Rodrigo de Cota» (70), y decidió componer la obra en quince días durante unas vacaciones (70-71).

Entre la bibliografía disponible para estudiar el problema de autoría caben destacarse, entre otros, los trabajos siguientes: Anna Krause, "Deciphering the Epistle-Preface to the Comedia de Calisto y Melibea» en Romanic Review 44 (1953): 89-101, Martín de Riquer, "Fernando de Rojas y el primer acto de La Celestina» en Revista de Filología Española 41 (1957): 373-395, Charles Faulhaber, «The Hawk in Melibea's Garden» en Hispanic Review 45 (1977): 435-450.

3. Se entienden los términos «significado» $y$ «función» tal y como son definidos por Roland Barthes en "Introduction to the Structural Analysis of Narratives» (1982). Como él sugiere, si se toma un texto debe leerse intentando localizar y caracterizar las formas o los códigos que hacen posible su significado. Es esencial localizar las «avenidas de los significados» en las que el objetivo es examinar «la pluralidad del texto» y "su significado» (255).

4. Hay que apuntar que si bien las propuestas teóricas de Barthes y Bajtin son aplicadas normalmente para el análisis de obras narrativas, en este estudio se consideran del todo apropiadas para aproximarse al análisis de LC, al concebir ésta como una obra "agenérica» en términos de lo que Gilman en su momento explicó. Para ello, se ha obviado el problema del género de la obra para considerarla como un producto híbrido que combina tanto el género narrativo como el dramático caracterizado por ser "puro diálogo» en sí mismo. 
locus amoenus. El huerto no sólo es el lugar en donde se propician las relaciones amorosas entre los personajes de Calisto y Melibea, sino también en donde se consuma el acto sexual entre ellos para llegar finalmente al desenlace trágico de sus muertes allí. ${ }^{5}$

Se pretende así responder a la siguiente pregunta: ¿Es acaso el huerto de Melibea una variación del cronotopo del hortus clausus que parodia el locus amoenus tradicional característico de la producción literaria medieval y moderna española? Se examina cada uno de los actos de la obra en los que el huerto es presentado como el lugar en el que la trama de la obra se desarrolla (actos XIV, XIX y XX) para analizar dos aspectos en concreto. Por un lado, se pretende enmarcar el cronotopo del huerto como representación de la naturaleza que termina transformándose en posibles conceptos estéticos, morales, filosóficos y religiosos. Por otro, se busca establecer las implicaciones entre los distintos significados y funciones posibles a los que la representación del huerto alude por ser éste sitio en el que la belleza, la fertilidad, la paz, el refugio e incluso la muerte tienen cabida.

\section{El huerto como cronotopo bajtiniano}

Se FUnDAMENTA el análisis de los actos XIV, XIX y XX, en el que el huerto de Melibea aparece (re)presentado, bajo las siguientes premisas teóricas bajtinianas. Se toman en cuenta aquí las relaciones espacio-temporales inherentes al concepto de cronotopo bajtiniano para el estudio espacial del huerto de Melibea dentro de la obra como «literally 'time space'... the intrinsic connectedness of temporal and spatial relationships... artistically expressed in literature» (Bajtin 1968, 84-85). El cronotopo juega pues un papel importante por sí mismo para entender el momento histórico en el que la obra literaria se produce. La historicidad espacio-temporal se deriva no sólo del contexto socio-histórico al que pertenece la obra, sino también de la serie de producciones y recepciones de otras obras en ese determinado momento. Esto es de vital importancia si se considera sobre todo a LC como una obra que aparece justamente en transición entre dos etapas históricas, la medieval y la renacentista.

Si se piensa además en el hecho de que la obra misma es puro diálogo y de que el cronotopo bajtiniano como conexión espacio-temporal es el reflejo de una misma realidad (la del autor), entonces ¿por qué no expondrá Fernando de Rojas sus puntos de vista sobre los diversos problemas sociales que aquejaban al mundo en el que vivía a través de los diálogos de cada uno de los personajes? ¿Será normal encontrar entonces una parte

5. Es precisamente tras la introducción de estas dos muertes en el huerto de Melibea donde radica una de las mayores variaciones correspondientes con el cronotopo tradicional del locus amoenus que se propone estudiar aquí. 
de Fernando de Rojas en la caracterización de sus personajes, entre ellos Melibea? Las respuestas a estos interrogantes llevan a anticipar que el análisis del huerto, como parodia de una tradición literaria en el caso de LC, va mucho más allá de ser un simple elemento irónico. Subvierte también un mensaje (el cristiano) y pone de relieve una problemática social (la de los marginados, fuesen mujeres o conversos).

Como afirma Bajtin en Rabelais and His World (1968), la organización del universo renacentista cambia con respecto al medieval debido a que las propias relaciones verticales que se establecen durante el Medioevo se transforman en horizontales en el Renacimiento. En estas relaciones horizontales, el cuerpo humano se entiende como signo de organización del cosmos, según la explicación teológica, en la que su cabeza es el paraíso (Dios), y el hombre y la mujer y sus extremidades son el infierno (el demonio). Este cambio en la percepción de la organización del cosmos y en los elementos que lo componen, lo explica Bajtin de la siguiente manera:

[In] the medieval... cosmos... all degrees of value correspond strictly to the position in space, from the lowest to the highest. The higher the element on the cosmic scale (the nearer to the [quintessential matter]) the more nearly perfect was this element's quality...

The Renaissance destroyed this hierarchical picture of the world; its elements were transferred to one single plane, and the higher and lower stratum became relative. The accent was placed on "forward» and «backward»... This cosmos was no longer moving from the bottom to the top but along the horizontal line of time, from the past to the future. $(363-365,402)$.

Si es así, a través de las representaciones que del huerto realiza, Fernando de Rojas pone de manifiesto el gran descontento social en el que los cristianos nuevos se encontraban. Primero, por la situación personal que cada uno de ellos tenía como converso - en la que Fernando de Rojas es sólo un ejemplo entre muchos-, y segundo, por el malestar colectivo en el que la sociedad se encontraba al ser éste un momento de cambio entre las relaciones que regían al universo. Las relaciones de tipo vertical se transforman pues en horizontal al atender a la organización del mundo y de la sociedad, tal como lo explica Bajtin. Se asiste así a una transformación a la hora de concebir las relaciones entre pasado y futuro, o bien, entre las falsas promesas de los cristianos viejos y lo que el destino les depararía a los conversos. Esto es precisamente lo que este análisis demostrará más adelante. 


\title{
3. El huerto de Melibea como locus amoenus: antecedentes y significación
}

\begin{abstract}
Calisto. No ay otra colación para mí sino tener tu cuerpo y belleza en mi poder; comer y beber dondequiera se da por dinero y cada tiempo se puede aver y cualquiera lo puede alcançar, pero lo no vendible, lo que en toda la tierra no ay ygual que en este huerto, ¿cómo mandas que se me passe ningun momento que no goze? (324)
\end{abstract}

A LO LARGO de la tradición judeocristiana, la representación del jardín en la literatura de alguna manera se ha relacionado siempre con el paraíso terrenal. Como sugiere A. Bartlett Giamatti (1966), el tema del jardín se ha presentado a los hombres y mujeres con el fin de recordarles que una vez existió un amor perfecto (el de Adán y Eva) en armonía en un lugar hermoso (el Edén) hasta que los primeros padres en la historia de la humanidad pecaron y fueron expulsados de tan maravilloso lugar. Durante la Edad Media, los padres y doctores de la Iglesia, desde los santos hasta los monjes, se dedicaron a teorizar y especular sobre tan especial lugar: ¿dónde estaba?, ¿quiénes lo habitaban?, ¿cómo era? y ¿qué significaba?

La cristiandad fue así elaborando y apropiándose de un imaginario colectivo en el que el paraíso fue visto como lugar de armonía y reposo. La épica renacentista, que se caracterizó precisamente por las muy diversas representaciones que de los jardines realizaba, se plasmó en la producción literaria de la época. El concepto del jardín fue asociándose con el del paraíso como locus amoenus y fue representando asimismo las fuerzas antagónicas que se enfrentaban en los poemas del Renacimiento. Por ejemplo, los conflictos entre herencia cultural vs. cultura cristiana, amor vs. deber, mujer vs. Dios, ilusión vs. realidad fueron algunos de los temas que abrieron paso al uso de los jardines como imágenes de la épica. Se llegó finalmente a asociar el paraíso con el jardín perfecto en el que la armonía y el equilibrio reinaban recordando el estado del cuerpo y del alma que una vez se poseyó y que se perdió a causa del pecado original de Adán y Eva. ${ }^{6}$

6. Es interesante hacer mención a las dos escuelas de pensamiento que durante la Edad Media discutieron la naturaleza, ubicación y accesibilidad al paraíso terrenal. Por un lado, la perteneciente a Ambrosio y Juan Crisóstomo que siguió las tendencias espiritualistas y alegorizantes del paraíso terrenal como símbolo del hogar celestial de las almas y del reino de los cielos. Otros dentro de la misma tradición observaron el paraíso como una imagen de la ciudad celestial. Por otro lado, la escuela opuesta caracterizó al paraíso terrenal como un lugar terrestre, parte inaccesible del planeta, en donde el ser humano tenía como objetivo metafóricamente la búsqueda de éste con el fin de hacer realidad sus sueños (Giamatti 14-15). 
Si el locus amoenus sirve entonces para designar al "lugar ameno» dentro de la producción literaria, en este trabajo se parte de la interpretación aportada por Giamatti (1966) para entenderlo además como «lugar de amor». Tal como Giamatti sostiene es difícil desligar su significado de mero «lugar ameno» con el de «lugar de amor». Es precisamente este último el sitio en el que el amor idílico se presenta como motor, llevando consigo diferentes connotaciones que hacen referencia a las representaciones del paraíso y de los personajes de Adán y Eva, que se analizan aquí. Se entiende por ello que tanto "lugar ameno» (jardín) como "lugar de amor» (paraíso) son significados en sí mismos equivalentes que se corresponden con el locus amoenus tradicional, en el que un jardín se asocia así con el paraíso terrenal de la tradición judeocristiana (3-7).

\section{El «primer» encuentro y el simbolismo del halcón}

ANTES DE ENTRAR de lleno en el análisis de cada uno de los actos correspondientes al huerto de Melibea, es necesario considerar en primer lugar la problemática concerniente a la primera escena del acto i de LC. ${ }^{7}$ Dentro de ésta, cabe considerar el elemento espacial en el que la primera escena del acto I toma lugar. ${ }^{8}$ Si en el argumento del primer acto se informa al

7. La crítica literaria ha abordado el tema desde muy diversos puntos de vista. Tal como Donald McGrady (1994) ha señalado, se ha estudiado el acto I enfocándose en diferentes aspectos, tales como: 1) la autoría de los argumentos de cada uno de los actos que componen la obra; 2) la aparición del halcón en el argumento del acto I que luego no aparece dentro del texto mismo de dicho acto ni de la obra; 3) la incógnita de si Calisto y Melibea se conocen aquí por primera vez, o bien, si ambos personajes ya habían sido presentados antes de la entrada de Calisto a "la huerta»; 4) el lapso de tiempo que separa la escena 1 de la escena 2 dentro del acto i; y 5) el hecho mismo de que el comienzo de la obra es un tanto abrupto, no siendo lo comúnmente característico de las producciones de los géneros narrativo o dramático del momento.

En este sentido, es importante señalar que para McGrady (1994) cada uno de estos aspectos están interrelacionados entre sí y que la clave para explicar tales interrogantes radica en el hecho de que el manuscrito conocido por Fernando de Rojas y del cual él reprodujo el primer acto estaba incompleto, faltándole algunos de los folios iniciales. Según el estudioso, Fernando de Rojas habría comprendido así el contenido general de los fragmentos perdidos a través de un lector o lectores mayores que él. Si bien la primera parte de su argumento puede resultar válida en tanto serviría para suponer que Rojas pudiera haber conocido más sobre el comienzo del acto i que lo que ha llegado hasta los lectores hoy en día sobre el contenido "misterioso» de este acto, considerando que el mismo Rojas pudiera haber completado o cambiado dicho contenido, el planteamiento sostenido por McGrady que apoya el hecho de que Fernando de Rojas hubiera llegado a informarse acerca del contenido del primer acto a través de otras personas puede ser en parte discutido. Se plantea la pregunta de ¿cuáles son las pruebas con las que se cuentan hoy en día para llegar a suponer que el manuscrito del primer acto hubiera circulado por otras manos diferentes a las de Rojas antes de las suyas? Tomando en cuenta que McGrady en ningún momento las menciona, ¿cómo es posible suponer esto?

8. A este respecto cabe apuntar que si la crítica se ha dividido entre sostener que la escena primera toma lugar, por un lado, en el huerto de Melibea o, por otro lado, en cualquier otra 
lector de que Calisto entra en una huerta siguiendo a un halcón que le pertenece y que allí encuentra a Melibea, en ningún momento se deja claro que este huerto (o huerta) sea precisamente el de la joven. ${ }^{9}$ Podría ser cualquier otro jardín, "una huerta cualquiera», y no necesariamente la de la protagonista que aparece en esta primera escena. Tampoco hay ningún "elemento descriptivo» que lleve al lector a saber con exactitud dónde tiene lugar la escena sino que, por el contrario, emerge una ambigüedad que no queda resuelta ni en el argumento ni en el texto del acto I.

A diferencia de lo sostenido por Riquer (1957), si se toma en cuenta que la entrada que hace Calisto es en "una huerta cualquiera» y no en la de Melibea, esto lleva a pensar que los personajes no tendrían por qué haberse conocido o encontrado antes. Por el contrario, Calisto y Melibea pueden haberse conocido precisamente en este momento, siendo por tanto este encuentro el primero entre ellos. ${ }^{10} \mathrm{Si}$ en el texto no se cuenta con ninguna referencia concreta en cuanto al tiempo que hace que se conocen ambos personajes, una de las tendencias más naturales pudiese ser entonces la de asumir que es "aquí» y "ahora» cuando lo hacen. Dicha tendencia se apoya así en los mismos principios del amor cortés y del amor a primera vista característicos de la producción literaria de entonces, que abarca desde la producción literaria medieval hasta la correspondiente al Siglo de Oro español, aunque con ciertos matices que parodiarían al amante cortés.

Entre estos matices deben mencionarse dos. Primero, la furia misma de Melibea frente al «loco atrevimiento» de Calisto puede deberse al hecho de que Calisto no sigue las pautas del amor cortés sino que, por el contrario, las desobedece provocando por consiguiente la ira de ella. Segundo, la exteriorización de los propios sentimientos de Melibea a través de su furia puede ser vista además como otro elemento ajeno al mismo modelo

huerta, hay también otras interpretaciones acerca del espacio en el que esta escena acontece. Así, por ejemplo, para Riquer (1957) el encuentro se producía en una iglesia que Fernando de Rojas decidió cambiar por un jardín: "[M]e parece que es posible concluir que la primera escena de La Celestina primitiva no se desarrollaba en el huerto de Melibea, que los dos jóvenes ya se conocían, que Calisto hacía tiempo que estaba enamorado de la doncella y que la búsqueda del halcón era totalmente un tema ausente. Y que es posible, en cambio, que la escena transcurriera en una iglesia» (389). Si en este trabajo no se apoya ninguna de las conclusiones a las que Riquer llegó tras su estudio, lo verdaderamente importante parece ser el hecho de que él fuera el primer estudioso en apuntar la problemática referente a este tema».

9. Como sugiere Charles B. Faulhaber en su trabajo titulado «The Hawk in Melibea's Garden» (1977), la sintaxis de las oraciones muestra que los eventos son narrados en una secuencia cronológica en orden: 1) la entrada de Calisto en el jardín, 2) el encuentro con Melibea, 3) el enamoramiento, 4) la declaración de amor de Calisto.

10. El hecho de que los personajes sepan el nombre del otro no es indicador fiable para apoyar la idea de que éstos se conocieran con anterioridad, ya que en el ambiente de una ciudad castellana del siglo Xv-XVI es muy verosímil que los dos personajes supieran cómo se llamaba la otra persona. 
del amor cortés que se supone los enamorados deberían haber cumplido, al carecer Calisto de la humildad que debía supuestamente haber rendido a la dama a la que cortejaba.

¿Por qué esta misma escena entre los dos enamorados no es entonces una parodia más dentro del conjunto de las muchas que componen la obra? Independientemente de que esta primera escena hubiese sido extraída completamente del texto original del acto i llegado a manos de Rojas, o bien hubiese sido reestructurada a partir del mismo -o incluso hubiese sido añadida en su totalidad por Rojas dentro de LC-, lo que importa aquí es que el propio Rojas pudo ser consciente de querer presentar un modelo literario que parodiase al del amor cortés, fuese a través de la ruptura del código de sufrimiento silencioso (Green, 1953) o a través de los desvaríos heréticos del amante cortés (Truesdell, 1973), tal como hace Rojas también con el modelo literario del locus amoenus tradicional al presentar una variación del hortus clausus por medio del huerto de Melibea.

Paralelamente, debe tomarse en cuenta que a lo largo de la tradición literaria del amor cortés, el halcón fue visto como símbolo y metáfora alegóricos de la pasión, reflejándose en los poemas europeos, desde los alemanes y franceses hasta la iconografía italiana de la época. En dichas producciones, como afirma Weinberg (1971), el halcón estaba estrechamente vinculado a las posibles connotaciones lascivas que formaban parte de la mente de un pecador como «a traditional symbol for rapine, appetite and destruction» (137). Si el propósito de Fernando de Rojas hubiese sido entonces el de parodiar la teoría y la práctica del amor cortés, la (re)presentación alegórica-simbólica del halcón dentro del argumento del acto I de LC lo constataría por sí solo. Como sugiere E.M. Gerli (1983), la escena de apertura de LC refleja en sí misma además una larga tradición del simbolismo característico proveniente de la literatura medieval europea que se correspondía con "la caza del amor» como alegoría común a las vicisitudes de la pasión.

El autor parodia así las mismas convenciones del cortejo tal y como fueron plasmadas por la tradición medieval, especialmente dejando a un lado la correspondiente a la del amor liderado por la pasión que puede llegar a culminar en consecuencias nefastas. La pérdida del halcón de Calisto pone de manifiesto una imagen que se sustenta sobre los temas de la pasión y la destrucción, anticipando los mismos tipos de amor y de literatura que son tratados en LC, tal y como Gerli (1983) sugirió:

Calisto's hawk is a complex emblem that consciously announces the type of love and literature that is the subject of the Celestina. In essence, it heralds the work's major thematic intentions: the portrayal of the clash between reality and chimerical courtly love, while foreshadowing the human violent tragedy that 
befalls those who indulge themselves in its fantasies and dissipations. (100)

El halcón sirve por tanto como la llave para entender el mensaje que subvierte LC. Si la imagen del halcón, en un primer nivel, comunica un propósito moral y artístico dentro de la tradición literaria europea, la misma imagen, en un segundo plano, sirve como elemento irónico que establece las consecuencias fatales a las que el amor pasional está sujeto dentro de la producción literaria del momento. ${ }^{11}$

\section{La parodia del locus amoenus: (des)virtudes cristianas en los confines del huerto}

MeLiBEA. Lucrecia, vente acá, que stoy sola; aquel señor mío es ydo; conmigo dexa su coraçón, consigo lleva el mío. ¿Asnos oydo?

LUCRECIA. No, señora, que durmiendo he stado. (287)

EL ACTO XIV abre con Melibea en el huerto esperando a Calisto mientras conversa con Lucrecia. Melibea está preocupada y lo primero que le expresa a su criada son posibles especulaciones del porqué de la tardanza de su enamorado. Melibea escucha repentinamente unos pasos que se aproximan y deja rápidamente de lado tales especulaciones. En eso llega Calisto acompañado de sus criados Sosia y Tristán, quienes le ayudan con una escalera a cruzar las paredes del huerto. Calisto les indica que permanezcan del otro lado, en el exterior del huerto, y pronuncia así las siguientes palabras: "Quedados, locos, que yo entraré solo, que a mi señora oigo» (284).

Esta primera parte del acto XIV resulta bastante interesante por observarse ya aquí una de las primeras variaciones con respecto al jardín o el huerto como locus amoenus tradicional que presenta la producción medieval y la literatura del amor cortés. Si el huerto se había presentado hasta entonces como un lugar cerrado, amurallado e inaccesible, el de Melibea consigue ser profanado por la presencia de Calisto, que trepa por sus paredes para entrar en él, y viola la intimidad y privacidad que sus muros

11. Resulta interesante el artículo de Albert I. Bagby, Jr. y William M. Carroll bajo el título «The Falcon as a Symbol of Destiny: De Rojas and Shakespeare» (1971). En este trabajo, ambos autores demuestran que el primer acto de LC utiliza el halcón con el fin de dramatizar el primer encuentro entre los futuros amantes Calisto y Melibea, tal como lo hará unos años más tarde William Shakespeare en su obra The Winter's Tale. Para estos autores, el primer encuentro entre los enamorados catapulta al mismo Calisto hasta la tragedia al violar el código social del amor cortés ante su irrefrenable pasión y deseo carnal que sólo pueden resultar en desastre y muerte. 
en principio protegen. Si el hecho de que sea un lugar cerrado es precisamente para guardar y preservar tanto la riqueza y la belleza presentes allí como la vida de quienes lo habitan, desde personas hasta flores y frutos, Calisto logra vencer el obstáculo para hacerse con lo supuestamente inalcanzable y hermoso que hay en el huerto: Melibea. No sólo hace caso omiso de la prohibición de entrar en un lugar prohibido, sino que además allí mismo consigue mantener una relación sexual con la propia doncella a la que rinde cortejo.

En otras palabras, Calisto se inmiscuye en donde no es bien recibido - al menos no lo sería por Pleberio-, para terminar haciendo de las suyas sin límites posibles, estén o no establecidos. Este hecho se corresponde, pues, con una violación del espacio privado por parte de aquellos a quienes sí se les permite su estancia, previa invitación de antemano, o bien, por parte de quienes lo habitan, lo cuidan o simplemente lo poseen. Tal es así, si se toma en cuenta sobre todo que a lo largo de la producción literaria medieval el tema del amor transcurre en un jardín o huerto, que llega a ser una estancia perfecta para que la historia de amor sea la única protagonista entre dos enamorados. Solamente los personajes malvados como, por ejemplo, la serpiente en el paraíso terrenal, son capaces de violentar este espacio, o bien de apoderarse de él, tal y como aquí sucede con el mismo Calisto.

Calisto pone así en entredicho tanto la vulnerabilidad de las paredes del huerto como la tarea de protección que éstas tienen al conseguir trepar por sus muros y adentrarse en él. En otras palabras, Calisto consigue penetrarlo, tal y como lo hace al acostarse más tarde con Melibea. Lo que Fernando de Rojas ya nos puede estar insinuando posiblemente aquí es lo frágil de tal protección. Su mensaje es que independientemente de los muros que posea el huerto, éstos nunca son lo suficientemente poderosos como para asegurarse una completa protección y evitar una invasión imprevista. A fin de cuentas, tampoco es posible predecir en qué momento una relación sexual tendrá lugar.

No importa ni el tamaño ni la altura de las paredes porque siempre es posible vencerlas. Además, si el huerto se había concebido como un espacio secreto, lo cierto es que aunque sea prohibido puede conquistarse y también violarse. Su delicadeza como lugar de refugio es por tanto más cuestionable de lo que se había pensado, ya que una mera norma o regla de prohibición no sirve para impedir su fractura, al igual que tampoco su estructura, forma o tamaño la imposibilitan. Ni siquiera Pleberio, que ha edificado torres y adquirido honras, consigue que Melibea conserve su estado virginal.

Por medio de la entrada de Calisto, Fernando de Rojas va sentando las bases para una parodia de los mismos principios que rigen la existencia del huerto como lugar idealizado y símbolo de perfección. En este jardín la naturaleza y el género humano se encuentran presentes en un mismo 
sitio y a la vez: en una unidad espacio-temporal que les es común a ambos, o en lo que sería, en otras palabras, el cronotopo bajtiniano de unidad de espacio y tiempo. Este binomio espacio-temporal no sólo sirve para recordar la creación del mundo y de los hombres en las figuras de Adán y Eva, sino que también pone de manifiesto que, aunque los primeros padres fueron pecadores, también fueron capaces de redimirse.

La coordenada espacial funciona entonces aquí para demostrar un hecho enmarcado dentro del mismo contexto histórico-social que envuelve LC y la producción y recepción de otras obras durante el período de transición entre el Medioevo y el Renacimiento. Este hecho es precisamente el de la superación de un tipo de literatura que ya no sirve como fuente de inspiración para los escritores del momento, sino que, por el contrario, se convierte únicamente en motivo para parodiar: la referida al amor cortés.

Un ejemplo de esta misma parodia son además las palabras pronunciadas por Melibea al entrar Calisto en el huerto. Desde abajo, ella le indica: "Es tu sierva, es tu cativa, es la que más tu vida que la suya estima» (284). Una vez más, salta a la vista que lo que Fernando de Rojas puede proponer aquí es marcar las diferencias entre lo que Melibea dice, por un lado, y lo que la dama del amor cortés no expresaría, por otro. Se contraponen así las diferentes actitudes entre una doncella agresiva y otra sumisa, o bien, entre una Melibea que se mueve por su propio pie y otra que se deja llevar acatando las reglas del mismo amor cortés.

Asimismo, Melibea no duda en iniciar una «supuesta» defensa en favor de su virginidad: "Guarte, señor, de dañar lo que con todos tesoros del mundo no se restaura» (284). Para luego terminar ofreciéndole a Calisto un contacto físico superficial, a lo que éste sugiere: «¿No quieres que me arrime al dulce puerto a descansar de mis passados trabajos?» (285). Esta situación, al menos, le da pie a Melibea para seguir defendiendo su estado de doncella antes de terminar «rindiéndose» por completo a los pies de Calisto, tal y como se observa en la breve interpolación de la Tragicomedia cuando la doncella replica: "Bástete, pues ya soy tuya, gozar de lo esterior, desto que es propio fruto de amadores; no me quieras robar el mayor don que la natura me ha dado; cata que del buen pastor es propio tresquilar sus ovejas y ganado, pero no destruyrlo y estragallo» (285). Si Melibea, en un primer momento, parece defender su estado de pureza, termina por acceder ante las caricias de Calisto, que no consigue controlar ni dominar su pasión. Dicha pasión tampoco se conforma con el mero acto sexual per se, sino que, por el contrario, va más allá. Calisto no sólo demuestra que parte de su deseo sexual es el de querer poseer a Melibea, sino que también expresa cierta apetencia que podría calificarse de exhibicionista, muy fuera de lo común, al permitirle a Lucrecia que se quede en el huerto para presenciar el acto sexual: «iPor qué, mi señora? Bien me huelgo que estén semejantes testigos de mi gloria» (285). 
Se cuestionan una vez más los principios de la literatura del amor cortés, porque Calisto pasa de cortejar simplemente a la dama a hacerle el amor enfrente de su propia criada. En la tradición literaria medieval, esta relación sexual es inconcebible, porque su objetivo es más bien el de presentar las aventuras y desventuras del caballero para conquistar a la dama y no el de referirse a una relación sexual que se presente explícitamente al lector. Es más, si se (re)presenta el jardín o el huerto dentro de la tradición medieval como lugar en el que la pareja de enamorados se encuentran juntos, el espacio sólo les permitiría que se conozcan de manera superficial por medio del cortejo y de la adulación a la dama, negando así cualquier tipo de actividad sexual y explícita entre los propios enamorados.

Además, a un nivel superior de análisis, el hecho de que Calisto invite a otros a observar el desfloramiento de Melibea, en este caso a la criada, rompe también con las propias tradiciones judeocristianas existentes hasta el momento, sirviendo para parodiar los principios que se establecen dentro de la producción literaria existente de entonces. Hay que tomar en cuenta también que la construcción moral-religiosa judeocristiana empieza a partir de este momento a explicar y a justificar las relaciones sexuales sólo en casos en los que la reproducción y procreación de herederos tienen cabida, bajo los auspicios del matrimonio. Dichas relaciones se entienden más tarde como algunas de las muchas funciones que la familia como núcleo social debía desempeñar. Ninguna relación extramarital se acepta y mucho menos si lo que se pretende de ésta es la búsqueda del mero placer sexual, tal y como las literaturas eclesiástica y legal de la época se ocuparon de desarrollar llegado el Concilio de Trento (1563). Se equiparan así los conceptos de pecado y delito como sinónimos en los ámbitos religioso y judicial que rigen a la sociedad castellana de transición entre el Medioevo y el período renacentista.

Tras la consumación del acto sexual y con el placer que reconoce Melibea haber tenido como ese "breve deleite», y antes de sentir la frialdad con la que Calisto se marcha al marcar el reloj las tres, un "supuesto" sentimiento de culpa y remordimiento es, a nivel superficial, lo único que parece quedarle a la ex-doncella:

¡O mi vida y mi señor! ¿cómo has quisido que pierda el nombre y corona de virgen por tan breve deleyte? ¡ $\mathrm{O}$ pecadora de ti, mi madre, si de tal cosa fuesses sabidora, cómo tomarías de grado tu muerte y me la darías a mí por fuerça; cómo serías cruel verdugo de tu propia sangre; cómo sería yo fin quexosa de tus días! ¡O mi padre honrado, cómo he dañado tu fama y dado causa y lugar a quebrantar tu casa! ¡O traydora de mí, cómo no miré primero el gran yerro que se seguía de tu entrada, el gran peligro que sperava! (286). 
Sin embargo, es evidente que estas palabras de Melibea, más que un lamento de la pérdida de su virginidad, lo que hacen es parodiar la situación en la que se encuentra, llegando a mostrar ciertas contradicciones en el discurso que ella misma pronuncia. Si Melibea parece culpar a Calisto de la pérdida de su nombre, con la consiguiente deshonra de ella y de su familia, no parece haber ningún indicio a lo largo del texto del acto XIV ni de la obra en general en el que la doncella ofrezca resistencia ante tal situación. Lo más que hace, en un primer momento, es pronunciar una «supuesta» defensa en favor de su estado de castidad que le permite, ante los ojos de Calisto, ser la muchacha pura y virginal que como doncella se espera que sea. Es más, en sus propias palabras, el «breve deleite» es prueba de la satisfacción que el acto sexual con su amante le ha dejado y que ella misma esperaba y deseaba. Si no, ipor qué habría de permitirle a Calisto la entrada en el huerto?

En una lectura entre líneas, las últimas palabras de su plegaria lo corroboran más aún: " $¡ O$ traydora de mí, cómo no miré primero el gran yerro que se seguía de tu entrada, el gran peligro que sperava!» (286). Sería difícil pensar que la misma Melibea no supiese lo que Calisto se proponía después de haber acordado con ella una cita privada tras las paredes del huerto. Además, si Melibea se había presentado un tanto agresiva y a la defensiva en otros encuentros con Calisto, por ejemplo, en la primera escena del acto I, se plantearían las siguientes preguntas: ¿por qué no le dijo a Calisto con la misma actitud que no continuase o parase sus caricias?, ¿por qué le permitió que prosiguiese hasta "deshonrarla»?, ¿por qué no expresó desacuerdo con la petición de Calisto de que Lucrecia permaneciera allí como «testigo de su gloria»?

De cualquier forma, las respuestas a estas mismas preguntas llevan a sugerir, fuese el caso que fuese, que el verdadero interés de Melibea es el de consumar una primera relación sexual con Calisto, aunque pudiese parecer ocultarlo tras las palabras de desdicha y de pena que pronuncia frente a su criada Lucrecia. Es más, ¿̇no son estas palabras una forma entonces de justificar su acción frente a los ojos de Lucrecia y «al que dirán» de sus padres si se enterasen de hasta donde ha llegado su hija con el joven Calisto? Lo que resulta importante es que ni las circunstancias ni la presencia de otras personas le impiden a Melibea, ni a Calisto, llevar a cabo su propósito de disfrute y gozo sexual, tras acostarse juntos en el huerto. Ella misma es consciente de ello y por eso pronuncia las palabras finales de esta escena, invitando a Calisto para las noches venideras:

Señor, por Dios, pues ya todo queda por tí, pues ya soy tu dueña, pues ya no puedes negar mi amor, no me niegues tu vida [de día passando por mi puerta: de noche donde tú ordenes]. Mas las noches que ordenares sea tu venida por este secreto lugar a la mesma hora, por que 
siempre te spere aperçibida del gozo con que quedo, sperando las venidas noches (287).

Ahora bien, si el tema del jardín o del huerto dentro de la tradición medieval expone que es éste el espacio ideal de perfección, en el que la mujer pura, que conserva su virginidad, es la única capaz de encargarse de su cuidado, lo que en este acto se encuentra es precisamente el caso contrario. Melibea ya no es la doncella inocente, sino la mujer transformada en tentación para el hombre, según los mismos postulados de la doctrina judeocristiana. Tampoco es la mujer pecadora que ha sido tentada por una serpiente ni un demonio, sino que ha actuado de esa forma por decisión propia. Su misma capacidad para decidir, su libre albedrío es lo que la ha llevado a la situación en la que se encuentra. No por ello es criticada, paradójicamente, por Fernando de Rojas.

Por el contrario, resulta más interesante ver que el autor de LC se sirve de ella y de su condición de ex-virgen para presentar una parodia más del locus amoenus tradicional y de la literatura del amor cortés de época medieval. El huerto es el lugar que le permite a Melibea comportarse como quiere, incluso cuando viene a ser una extensión de la vida privada porque, aunque es cerrado, le posibilita alejarse del control ejercido por sus padres. Dicha extensión es también un espacio liderado por los principios que rigen la vida pública de los individuos de entonces. Si forma parte de la vida privada porque pertenece a la estructura espacial del hogar, se constituye también como componente de la vida pública al permitir la entrada a otros individuos provenientes de esta misma esfera, como es el caso de un Calisto que llega del exterior.

Si Melibea pone en peligro su condición de doncella al ser encontrada en tales acciones $y$, sobre todo, en compañía masculina, las posibles repercusiones que se esperarían de hallarlos juntos en el huerto podrían ser menores que si fuesen descubiertos ante «las rejas de la puerta» en las mismas circunstancias. Esto es así, sobre todo, porque el secreto no trascendería más allá de las paredes que conforman el hogar y, por ende, la esfera de lo privado, no viéndose afectada por completo su honra o la de su familia porque siempre se podría ocultar ante los ojos de los demás en aras del bien familiar.

Paralelamente, el comportamiento de Melibea supone también una parodia más de los principios del amor cortés, porque ella misma representa la antítesis de la mujer que guarda y cuida su virginidad por encima de todo. Para la dama del amor cortés no hay palabras ni caricias que la hagan fracasar en su intento de mantenerse casta y pura ante el amante que la enamora. Sin embargo, lo más relevante aquí es entender que la misma Melibea elige y desea acostarse con Calisto, expresando también implíci- 
tamente sus deseos, sin llegar a negarlos en ningún momento. Al menos, no hay prueba textual en LC que contradiga esta suposición.

Si Melibea no toma la iniciativa, de forma explícita, para potenciar el acto sexual por diferentes razones, al menos llegado el momento lo consiente. Por un lado, sería mucho pedir de una doncella de su condición social, cuando Fernando de Rojas lo deja ya entrever en el argumento de toda la obra, ya que se da a entender que no es precisamente Calisto el que persigue a Melibea: «donde a la presencia de Calisto se presentó la deseada Melibea» (83). Por otro lado, y partiendo de que esta contradicción en el argumento de la obra es una más de todas las que el autor de LC trabaja, tampoco Calisto le da mucha oportunidad a Melibea para hacerlo durante la primera escena del acto XIV, cuando en primera instancia ya empieza a acariciarla, replicando Melibea: "Por mi vida que aunque hable tu lengua quanto quisiere, no obren las manos cuanto pueden» (285).

Así pues, la misma unidad espacio-temporal postulada por Bajtin sirve para concluir que a lo largo de esta escena del acto XIV la función que rige las acciones trae a colación el mismo contexto histórico-social en el que vive el autor. No sólo se expresan conceptos morales y religiosos de la época, como el comportamiento de la mujer, el significado de la virginidad o la salvaguarda de la honra y del orden social, entre otros, sino que, además, se critican y parodian dichos conceptos. Bien puede ser por su condición de converso, bien por mero deseo del autor, lo importante aquí es observar el cuestionamiento de unos valores morales y sociales, que hasta entonces la literatura medieval había exaltado. Para Fernando de Rojas posiblemente estos valores podrían no tener la misma validez, si se toma en cuenta la misma hipocresía que caracterizaba y regía a la sociedad castellana de entonces a la hora de atender a los fundamentos sociales y religiosos que en teoría debían acatarse. Dicha hipocresía se expresaba así: mientras los mismos cristianos viejos promulgaban unos principios que había que seguir, éstos al momento de practicarlos los ignoraban. Y si la enseñanza cristiana era la de "predicar con el ejemplo» es bastante acertado afirmar que en la práctica esto no se daba y que Rojas como converso fue consciente de ello. Todas aquellas promesas que los cristianos viejos habían asegurado a los nuevos que se convertían, quedaron incumplidas sin hacerse realidad. Se mostró entonces cómo los mismos "anti-valores» en contra de los cuales se luchaban supuestamente eran al final acatados también por la misma sociedad que los rechazaba. Si bien, por un lado, se postulaba un principio, por otro se contradecía. Entre los muchos ejemplos existentes de estos, cabe señalarse aquel que promulgaba la igualdad de hombres y mujeres ante los ojos de Dios, para negarla posteriormente en las esferas públicas y privadas, y en los terrenos legal y religioso, afirmando que la mujer, por el hecho de ser mujer, 
debía de estar sujeta y sometida al varón, aunque a los ojos de Dios fuera

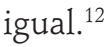

\section{Detrás de la parodia: mensaje subversivo y crítica social en el huerto}

Melibea. Señor, yo soy la que gozo, yo la que gano; tú, señor, el que me hazes con tu visitación incomparable merced. (324)

Si HASTA AQUí se ha analizado el huerto de Melibea como parodia del locus amoenus tradicional de la tradición medieval, los ejemplos de la (re)presentación del jardín en los actos XIX y XX son dos casos distintos. Si a un nivel superficial, la representación del huerto de Melibea del acto XIX puede observarse como parodia del amor cortés, a un nivel superior va mucho más allá. En este acto, Fernando de Rojas no sólo pone de manifiesto el carácter paródico que acompaña al huerto como espacio en el que el amor y el sexo entran en juego, sino que también ofrece su propia visión de cómo lo entiende, definiéndolo en función de un mensaje antimariano que se apoya también con la introducción de la muerte de Calisto en este acto y del suicidio de Melibea en el acto siguiente.

Además, no cabe duda de que la segunda escena del acto XIX está repleta de una gran carga erótica-sexual que se esconde tras la misma poetización que Melibea y Lucrecia hacen del huerto en un primer momento. Si se observa que Melibea y Lucrecia cantan la belleza y esplendor casi poéticos del huerto en la noche, éste sigue siendo también el lugar apartado y reservado en el que Calisto irrumpe para poseer una vez más a su enamorada. Se contempla aquí un gran número de referencias a la naturaleza y a su colorido, descripción que llega a ser subvertida con el mensaje de imaginar un mundo sin paredes, puertas, calles y habitaciones. Un mundo en el que sólo los árboles, las estrellas, los papagayos y los ruiseñores, entre otros, sean sus únicos límites posibles.

Esta poetización de la naturaleza además de recordar los elementos de la creación, aquéllos correspondientes al paraíso terrenal, pone de manifiesto también, a un nivel superficial, un canto a la Virgen María y a las virtudes cristianas que, finalmente, se subvierten. En palabras de Lucrecia:

12. Es importante resaltar que San Pablo al hablar de materia de fe expuso: «ya no hay judío, ni griego, no hay esclavo, ni libre, no hay varón, ni mujer, porque todos vosotros sois uno en Cristo" (Gálatas III, 28). Sin embargo, tanto los textos medievales emanados de la iglesia como los legales sustentan la inferioridad de la mujer y la necesidad de que ésta sea asistida por un hombre. 


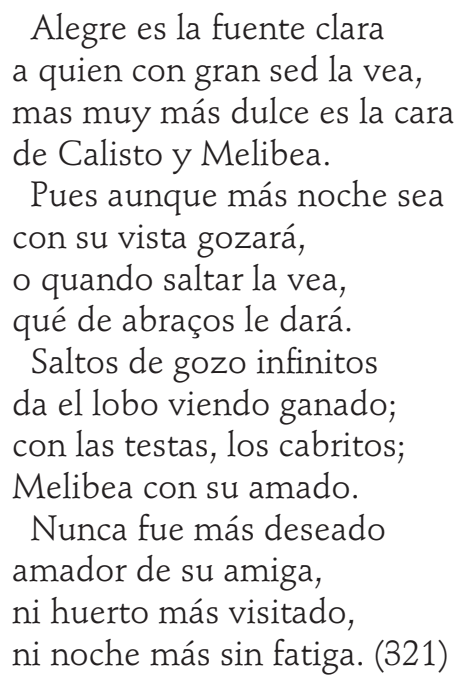

Esta subversión se observa en LC a lo largo de tres hechos concretos. Primero, el comportamiento de Melibea al consentir y desear la relación sexual con Calisto en el acto XIV; segundo, la muerte accidental de Calisto al final del acto xIx; y tercero, el suicidio de Melibea desde la torre en el acto Xx. Se subvierte también la misma ética mariana que, en un principio, en la escena parecía ser alabada por los personajes femeninos, hallándose una vez más aquí otra de las tantas contradicciones que son características de la pluma de Fernando de Rojas. Todo esto escondido tras un "Óyeme tú, por mi vida; que yo quiero cantar sola» (321) de Melibea en el que se sugiere que el gozo sexual es todo lo que espera de su aventura nocturna. La exaltación implícita de la Virgen y de sus virtudes cristianas, a través de elementos como «lirios», «azucena», "fuente», «estrellas», "lucero" ${ }^{13}$ (320-321), se transforma en un mensaje antimariano y, por consiguiente, anticristiano, que rompe con los principios de perfección y pureza que la literatura medieval pretendía hacer llegar a su público, tras representar al jardín como símbolo de la Inmaculada Concepción y de la virginidad y fertilidad que conllevaba. ${ }^{14}$

Si tanto Lucrecia como Melibea parecen presentar un canto al jardín, que recuerda al típico locus amoenus con sus flores (lirios, azucenas), olores, árboles, cielo (estrellas, noches) y aves (papagayos, ruiseñores), al fi-

13. Resulta interesante el libro Signs \& Symbols in Christian Art (1959) de George Ferguson, en el que se elabora todo un compendio de signos y símbolos que hacen referencia a la cultura cristiana, desde animales, pájaros, insectos, flores, árboles, plantas, hasta artefactos, objetos y vestidos religiosos, colores, números, etc. Entre estos símbolos, los lirios, las azucenas, la fuente, el agua, las estrellas, el lucero, se asociaron con la imagen de la Inmaculada Concepción y con el mensaje mariano que traía consigo.

14. "A garden enclosed is my sister, my spouse; a spring shut up; a fountain sealed» (Salomón, 4: 12; citado en Ferguson 23). 
nal llega a desvanecerse con la actitud permisiva y recurrente de Melibea al querer mantener relaciones sexuales con Calisto, dándolo a entender mientras espera "aquí assentada» (322). Al mismo tiempo, primero, las caricias de Calisto; segundo, lo directa y sincera que es Melibea a la hora de atender al contacto físico de su amante por encima de su ropa; y tercero, la predisposición de Lucrecia a acostarse con alguno de los criados, ponen de manifiesto una ruptura frente a los valores marianos y cristianos que han sido alabados anteriormente por ellas:

Melibea. (...) ¿Cómo mandas a mi lengua hablar y no a tus manos que estén quedas? (...) Dexa estar mis ropas en su lugar, y si quieres ver si es el hábito de encima de seda o de paño ¿para qué me tocas en la camisa?, pues cierto es de lienço. Holguemos y burlemos de otros mil modos que yo te mostraré; no me destroces ni maltrates como sueles. ¿Qué provecho te trae dañar mis vestiduras?

CALISTO. Señora, el que quiere comer el ave, quita primero las plumas.

LuCReCiA. (Mala landre me mate si más lo escucho; ¿vida es esta? Que me esté yo deshaziendo de dentera y ella esquivándose por que la rueguen. Ya, ya, apaziguado es el ruydo; no ovieron menester despartidores; pero también me lo haría yo si estos necios de sus criados me fablassen entre día, pero esperan que los tengo que yr a buscar). (323-324)

Hasta aquí sería evidente que el interés de Melibea es más el de proteger el estado de sus ropas que el de rechazar a Calisto y a sus caricias. No expresa ningún tipo de arrepentimiento ni se retracta por lo que ya ha hecho anteriormente, es decir, por haber perdido su virginidad. Si Melibea no representa el modelo de la santa o virgen, en la figura de María, que se mantiene casta por ser éste requisito de perfección y pureza para los cristianos, tampoco es la prostituta arrepentida, como María Magdalena, que reconoce sus errores. Por el contrario, Fernando de Rojas no pone en su boca palabras de humildad y arrepentimiento que lleven a la pecadora a reconocer su falta y redimirse. El caso es totalmente el opuesto. Al lado de Calisto, ella provoca que su criada al igual se excite sexualmente. El deseo sexual está presente por toda la escena y si es verdad que tanto Calisto como Melibea están dispuestos a consumar otra relación enfrente de Lucrecia, esta vez ella no quiere dejar de ser menos y participar también. Si no es acompañando en ese momento a los dos enamorados en un ménage à trois, Lucrecia es consciente de que será ella quien tendrá que ir a buscar a los criados si lo que pretende es hacer algo con ellos. La temperatura de la escena sube con los besos y las caricias que la misma Lucrecia presencia activamente hasta que de repente se interrumpe por las voces 
de los criados, que del otro lado de las paredes del huerto se enfrentan con los amigos de Centurio.

Se observa por tanto que más que una parodia del locus amoenus tradicional, esta escena dibuja un huerto en el que se subvierte un mensaje que a primera vista pareciese ser el cristiano, es decir, el de la exaltación del jardín y con éste el de la representación de María, su virginidad, y todas aquellas virtudes cristianas que le acompañan. Sin embargo, en una lectura entre líneas, es fácil notar que lo que pretende Fernando de Rojas no es precisamente referirse o exaltar tales valores, sino negar, más bien, todo matiz cristiano y didáctico que en un principio se le pudiese achacar a la escena. Esto es así, sobre todo, si se toma en cuenta la realidad del mismo autor: primero, por su condición de converso y, segundo, por el pesimismo que le acompañaba. Por un lado, un pesimismo generalizado a nivel social al ser ésta una época de transición entre períodos históricos; por otro lado, un pesimismo que caracterizó a los propios cristianos nuevos que vieron truncadas sus promesas. Si este es el caso, es entonces normal que no se pueda hablar de las intenciones didácticas de Fernando de Rojas, teniendo que desglosar el mensaje subversivo que transmite más minuciosamente.

Parecería aceptable afirmar que ya a este punto de la obra, Fernando de Rojas ha ido desvelando más y más el mensaje que verdaderamente se esconde en LC. Si en un primer momento hubiese podido ser acertado señalar que el propósito de la obra habría sido el de componer una Comedia o Tragicomedia en "reprehensión de los locos enamorados» con el fin de avisar "de los engaños de las alcahuetas y malos y lisonjeros sirvientes» (82), como afirma el propio autor en el material preliminar de su obra, llegado este punto es indiscutible la crítica anticristiana que presenta, alejando de ella cualquier rasgo didáctico. El proceso ha evolucionado por sí solo desde las primeras «contradicciones» $\mathrm{y}$ «ambigüedades» que se presentaban en sus inicios para culminar en el llanto de Pleberio. En este proceso, si el acto XIV sirve para parodiar al locus amoenus tradicional y a la tradición literaria del amor cortés, el xIX, por el contrario, contribuye a enmarcar dicha parodia bajo unos planteamientos éticos y morales que representan la ideología de Fernando de Rojas, permitiéndole cuestionar a la sociedad en la que vive y a la cultura religiosa a la que ha tenido que unirse. Sin dejar de atacar, claro está, el factor de la hipocresía social que sirve como punto de unión entre los dos. Así pues, el postulado bajtiniano de cronotopo serviría una vez más para poder explicar cómo la producción literaria en transición entre el Medioevo y el Renacimiento estaría sujeta a una degradación tanto del canon literario como del social al ser producto de la historia y de la sociedad en la que el autor escribe.

Del acto XIX queda todavía por analizar su última parte, que corresponde precisamente con la muerte de Calisto. Para ello, he preferido integrarlo con el suicido de Melibea, que tiene lugar en el acto Xx, con el fin de 
establecer posibles comparaciones. Sobre todo, si se toma en cuenta que ambas muertes se producen en circunstancias distintas. Mientras Calisto muere al caer accidentalmente de la escalera desde las paredes exteriores del huerto hacia la calle, Melibea se suicida tirándose desde la torre al jardín interior que hay en el huerto de la casa de su padre.

En cuanto a la muerte de Calisto, lo primero que salta a la vista es la respuesta de Melibea a ésta. Si Calisto muere accidentalmente, puesto que no hay ningún indicio en el acto o en el texto de que fuera por "castigo de Dios», Melibea toma la decisión de acabar con su vida tras darse cuenta de que es la única forma de "purgar con su culpa» (331). Pero ¿de qué culpa está hablando? ¿A qué se refiere? Independientemente de si las respuestas a tales preguntas fueran por amor a Calisto, por borrar su deshonra ante sus padres, o por no vivir apenada sin su amante, lo cierto es que ya su "remedio» también ha perecido (330). Calisto ha muerto y antes que él ha sido asesinada por Sempronio y Pármeno Celestina, que era la única capaz de remedar y rehacer virgos. Si es así, está claro entonces que de ninguna manera la vida de Melibea tiene ya sentido, sea sin su amante o bien sin su virginidad. Lo único que le espera es la pena y el dolor, producto de tan poco disfrute y gozo, en una sociedad en la que el honor y la honra dictaminan el futuro, aparte de, por supuesto, la cuna y la adscripción al estamento social al que se pertenece que no permite movilidad social posible.

Una vez más no hay indicios de enseñanza cristiana alguna. Si uno muere por accidente y la otra lo hace por decisión propia, considerando que el suicidio atentaba además contra las bases y los postulados cristianos, sería difícil apoyar que el autor pondría de relieve algún rasgo didáctico dentro de la obra. Por el contrario, Fernando de Rojas propone, más que dejar en la obra una moraleja o enseñanza de matiz cristiana, la crítica de una visión de mundo: la de los cristianos viejos. Fernando de Rojas deja entrever la respuesta a la pregunta: ¿es necesario para una mujer de la condición de Melibea morir antes que vivir fuera de tales preceptos? El autor habría sido consciente del pesimismo que envuelve a la sociedad en su conjunto y, por ende, a los conversos. Habría conocido lo problemático que hubiese sido para una mujer como Melibea el intentar sobrevivir en un mundo en el que la búsqueda del placer sexual y del amor no se le permitía según los estándares de la doble moral que regían a los géneros, y en la que al varón no se le condenaba. La única solución posible para Melibea hubiera podido ser la prostitución que en su caso, dada la condición social y económica de su familia, sería impensable.

Así pues, lo que Fernando de Rojas está haciendo aquí es un comentario en favor de la mujer exponiendo cómo su situación estaba condicionada, por un lado, por el hombre con el que vivía y, por otro, por su virginidad como una de las cualidades intrínsecas que debía mantener para poder sobrevivir en una sociedad en la que el orden era patriarcal. El autor de 
LC, en lugar de condenar a Melibea tal y como la doctrina cristiana lo hubiese hecho, le da a ésta la capacidad de decidir en todo momento: Melibea se mueve por su propio pie y dispone de su libre albedrío para enamorar a Calisto, acostarse con él y, finalmente, acabar con su vida. De hecho, Melibea puede ser vista entonces como una mujer que tiene que morir para poder ser escuchada, para que su queja y, por consiguiente, la crítica que elabora Fernando de Rojas, puedan ser pronunciadas y oídas. Pero, ipor qué habría otorgado Fernando de Rojas tanta independencia a Melibea? Si los personajes femeninos (Celestina, Areusa, Elicia, Lucrecia) dentro de LC son bastante activos, incluso algunas veces mucho más que los masculinos, lo cierto es que Fernando de Rojas expondría que la situación de los conversos en esa sociedad regida por los cristianos viejos, a fin de cuentas, no sería tan diferente a la de las mujeres que la integraban.

Los conversos y las mujeres por tanto compartirían una misma realidad que no le era extraña al autor de LC. Y es en ella donde Melibea, más que como perdedora, debe ser vista como ganadora. De hecho, Melibea vence varias veces; consigue a su amado y muere para que su voz sea escuchada. Si no, ¿por qué habría de pronunciar las palabras «De todos soy dexada» (331)? ¿No sería acaso la situación de los conversos parecida a la de la protagonista femenina? Si tanto mujeres como conversos se encontraban "desamparados» de la voluntad de Dios en la sociedad castellana de transición, y si se considera el gran realismo y verosimilitud con el que la crítica tanto ha caracterizado a LC, entonces, ¿no estaría Fernando de Rojas dibujando la sociedad en la que vivía? ¿No expondría el autor la problemática en la que sus «marginados» se hallaban? ¿A pesar de su condición social no se vería Fernando de Rojas como uno de estos marginados al ser un converso desencantado con su realidad, su sociedad y con quienes la organizaban, es decir, los cristianos viejos?

\section{Conclusión}

Si la PARODIA del locus amoenus tradicional, por un lado, pone de manifiesto la necesidad de superación de un estilo de producción literaria, no menos importante es el hecho de que, por otro lado, el mensaje antimariano y anticristiano que se presenta subvierte una doctrina religiosa que condena a la mujer, $y$, por analogía a los conversos, y en la que «una muerte» es lo adecuado para poder escapar de ella. Dicha muerte debe ser entonces vista como triunfo y no como fracaso porque si bien se constataría la capacidad «ficcional» que tenían las mujeres a través de LC para decidir, se pone de relieve también que el autor ya era consciente de los problemas sociales que afectaban a los más «indefensos». Sin importar que fuesen mujeres o conversos, ambos grupos estaban sometidos a los constructores, legisladores y únicos portadores de «la verdad» de un ré- 
gimen social controlado por y para cristianos viejos, y en el que ni las mujeres ni los conversos tenían cabida.

\section{Bibliografía}

BAGBY Jr., Alberto y William M. Carroll. "The Falcon as a Symbol of Destiny: De Rojas and Shakespeare». Romanische Forschungen 83 (1971): 306-10.

BAJTIN, Mijail. Rabelais and his world. Cambridge, MA: M.I.T., 1968.

- Teoría y estética de la novela: trabajos de investigación. Madrid: Taurus, 1989 (1975).

BARTHES, Roland. «Introduction to the Structural Analysis of Narratives.» A Barthes Reader. Ed. Susan Sontag. New York: Hill \& Wang, 1982.

BEARDSLEY, Theodore S. «Celestina, Act I, scene I: 'Ubi sint'?». Hispanic Review 52 (1984): 335-41.

BRYANT-BERTAIL. «Space/Time as Historical Sign: Essay on La Céléstine, in memory of Antoine Vitez». Journal of Dramatic Theory and Criticism 5 (1991): 101-120.

CANTALAPIEDRA EROSTARBE, Fernando. "La escena de la huertahuerto". Literatura Hispánica. Reyes Católicos y Descubrimiento. Dirección: Manuel Criado del Val. Barcelona: PPU, 1989, pp. 317-27.

CASTELLS, Ricardo. "Bakhtin's Grotesque Realism and the Thematic Unity of Celestina Act I»., Hispanófila 36 (1992): 9-20.

FERGUSON, George. Signs \& Symbols in Christian Art. New York: Oxford U P, 1959.

GERLI, E.M. "Calisto's Hawk And The Images Of A Medieval Tradition». Romania 104 (1983): 83-101.

GIAMATTI, A. B. The Earthly Paradise and the Renaissance Epic. Princeton: Princeton U P, 1966.

GREEN, Otis H. «La furia de Melibea». Clavileño 20 (1953): 1-3.

LECERTUA, J-P. «Le Jardin de Mélibée (Métaphores sexuelles et connotations symboliques ans quelques épisodes de La Celestina». Trames. Collection d'êtudes ibêriques 2 (1978): 105-38.

LIDA DE MALKIEL, María Rosa. La tradición clásica en España. Esplugues de Llobregat: Editorial Ariel, 1975.

MCGRADY, Donald. "The Problematic Beginning of Celestina». Celestinesca 18 (1994).

- «Entrando Calisto una huerta... and Other Textual Problems in The Celestina». Hispanic Review 63 (1995): 433-40. 
OROZCO DÍAZ, Emilio. "El huerto de Melibea (Para el estudio del tema del jardín en la poesía del siglo XV)». Paisaje y sentimiento de la naturaleza en la poesía española. Madrid: Ediciones del Centro, 1974, pp. 63-76.

PARKER, Alexander Augustine. The Philosophy of love in Spanish literature, 1480-1680. Edinburgh: Edinburgh U P, 1985.

RIQUER, M. "Fernando de Rojas y el primer Acto de La Celestina». Revista de Filología Española 41 (1957): 383-89.

ROJAS, Fernando de. La Celestina. Ed. Dorothy S. Severin. Madrid: Ediciones Cátedra, 1997.

RUGGERIO, Michael J. "The Religious Message of La Ceslestina». Folio 10 (1997): 69-81.

SANDERS, Ronald. "Interlude: In a Garden.» Lost Tribes and Promised Lands: The Origins of American Racism. Boston \& Toronto: Little, Brown and Company, 1978, pp. 133-40.

SHIPLEY, George A. "Non erat hic locus; the Disconcerted Reader in Melibea's Garden». Romance Philology 27 (1974): 286-303.

SNOW, Joseph T. Celestina by Fenando de Rojas: An Annotated Bibliography of World Interest 1930-1985. Madison: Studias Medieval, 1985.

STAMM, James R. "De 'huerta' a 'huerto', elementos líricos-bucólicos en La Celestina». La Celestina y su contorno social: Actas del I Congreso Internacional sobre La Celestina. Barcelona: Borrás Ediciones, 1977, pp. 81-88.

- La estructura de La Celestina: Una lectura analítica. Salamanca: Universidad de Salamanca, 1988.

SZERTICS. "A propósito de la primera escena de La Celestina». Confluencia 2 (1987): 15-21.

TRUESDELL, William D. A New Reading of Act I of the Celestina. Ph.D. Dissertation (1969): Brown University, 1969.

- "The Hortus Conclusus Tradition, and The Implications Of Its Absence, in The Celestina». Kentucky Romance Quarterly 20 (1973): 257-77.

WEINBERG, F.M. "Aspects of Symbolism in La Celestina». Modern Languages Notes 86 (1971): 136-277.

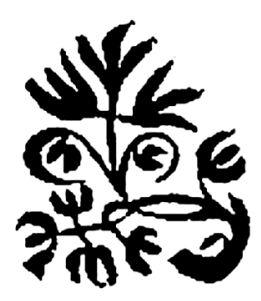


Sosa Velasco, Alfredo J. «El huerto de Melibea; Parodia y subversión de un topos medieval», Celestinesca 27 (2003), pp. 125-148.

\section{RESUMEN}

EL PRESENTE artículo explora los posibles significados y funciones (así como las connotaciones) que el huerto de Melibea tiene dentro del texto de LC. Comprender la fluidez de las relaciones entre representación, por un lado, y significación misma del huerto, por otro, es la meta de este análisis. Se pretende responder a la siguiente pregunta: ¿es acaso el huerto de Melibea una variación del cronotopo del hortus clausus, que parodia el locus amoenus tradicional característico de la producción literaria medieval y moderna española?

PALABRAS CLAVE: La Celestina, cronotopo, huerto de Melibea, hortus clausus, locus amoenus, parodia, subversión

\section{ABSTRACT}

THIS ARTICLE explores the possible meanings and functions (as well as the connotations) of Melibea's garden within LC. The main goal is to understand the relationship between the representation of Melibea's garden and its importance. The central question is: Could Melibea's garden be a variation of the chronotope of hortus clausus that parodies the traditional Spanish medieval and modern literary production?

KEY WORDS: La Celestina, chronotope, Melibea's garden, hortus clausus, locus amoenus, parody, subversion.

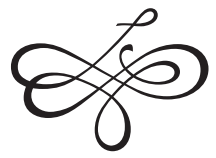

